\title{
BEING THROWN UNDER THE BUS AND RISING ABOVE THE FRAY: MAINTAINING AUTHENTICITY
}

\author{
Kristine Quade, Grand Canyon University \\ Amanda K. Beaver, Grand Canyon University \\ Laura Fry, Grand Canyon University \\ Daniela Bulmini, Grand Canyon University \\ Elvia Miller, Grand Canyon University
}

\begin{abstract}
This qualitative descriptive study was conducted to explore how female leaders describe remaining authentic when being scapegoated. The participants were 12 senior female leaders in either for-profit or nonprofit roles in Arizona. While not all women were able to maintain their authenticity during the scapegoating experience, the experience was transformational for all of them.

Keywords: authenticity, women in leadership, scapegoat, leadership

\section{INTRODUCTION}

Scapegoating is an old and refined practice that is often experienced in society today through social media. A scapegoat is a person or group made to bear the blame for the mistakes of others or to suffer in their place. Active blaming, recrimination, and negative typecasting are used to deflect responsibility for some failure from the perpetrator to the scapegoat, and often the reasons for this are hidden from view. The effect is that the guilty persons or groups are not punished and this provides a mechanism for them to gain control of inner chaos or understanding, and it gives them the opportunity to seize control, exert power, or form allegiances. (Ruch, Lees, \& Prichard, 2014). It is difficult to uncover the effects of scapegoating because the descriptions of those affected are often vague or abstract due to the multiple layers of the experience.

Though scapegoating can be an unconscious and mechanical behavior, at the same time the outcome leads to social cohesion and order. For example, consider the effects of Hitler's leadership on the Jews living in Europe. The genocide that occurred for many years was framed as building national pride for one group through the efforts to eliminate another group. It took many years for societal denial

to become clear and for counteractions to be taken, which resulted in a world war. According to René Girard (1986), scapegoating is a mimetic desire that repeats over and over through history as an imitation behavior that follows a cycle. Individuals who want the same thing form group ties to clash against and overcome the ideology of others and seek a new social order. Imbedded in this cycle are complex and cyclical patterns of human behavior.

The bigger question is whether scapegoating is a function of the human psyche, group effectiveness, or the drive for social order. According to the seminal work of John Weir (1975), initial identity formation is attributed to epistemology, or the foundation of values, beliefs, and truths as taught by parents, teachers, church, or friends encountered early in life. This epistemology shapes one's perceptions of the world and to how one responds to it. Through interactions with teachers, family, friends, television, and social media, one's identity will be reinforced or challenged. Chris Argyris (1962) indicates that there is a human tendency to deny or distort behaviors when encountering others who do not share the same epistemology because they appear as a threat. When threatened, the natural responses might include denial, anger, fighting back, silence, shock, helplessness,
\end{abstract}


deflection, retaliation, and blaming others. All these responses have been described as precursors to scapegoating.

As a phenomenon, blaming others for one's misdeed is a characteristic of all societies, and the act of sacrificing someone for selfish reasons remains a predominant behavior in human relationships. Scapegoating behavior is likely to occur during a crisis or impending danger because of strong decision making, a drive for power, or the inability to deal with differences. And yet, these phenomena still are not clearly understood. The idiomatic American English phrase "throw under the bus" is typically used to describe an act of betrayal. Allport and Postman (1948) explores the roots of racial prejudice and scapegoating between groups rather than within them. Giuseppe Bonazzi (1983) makes a distinction between expressive scapegoating, described as "widespread aggressiveness to release emotional tension" (p. 2), and instrumental scapegoating, which is "more calculated and designed to hide the flaws in the system or single-pushing the blame far into the system" (p. 2).The two most predominant forms of scapegoating are found in bullying through social media and the divisions created by political views. No longer are the individual and group level impacts the result of unconscious behaviors.

This shift from subtle scapegoating has developed new labels. The culture of blame, low morale, and feelings of powerlessness and stress studied by Allport and Postman (1948) has now become the need to understand the effects of bullying in grade school. According to Wheatley (2017), "communities and nations are disrupted by terrorist acts, cumbersome bureaucracies cannot deliver services, people retreat in self-protection and lash out in fear, angry citizens strike back at their governments, leaders stridently promise security and outcomes that they know can't be delivered, tensions between people reach hateful proportions, and confusion and exhaustion sink us into despair and cynicism" (p. 37). The question becomes, how do we break the scapegoating cycle?

This qualitative descriptive study explores how living authentically might be an approach fordealing with scapegoating behavior. The participants in this study were all senior-level women in either for-profit or nonprofit organizations in Arizona.
Each of the women described a scapegoating experience, but they were only able to learn from the experience by first defining authenticity as a leadership principle.

\section{AUTHENTIC LEADERSHIP}

Ask anyone for a definition of authenticity and a variety of definitions will emerge such as "behaviors that are aligned with clear values," "wholehearted presence," "always there," and "embracing my inner greatness." As a leadership concept, authentic leadership was first conceived of as an idea that embraced resources, structure, power, mission, meaning, and ultimately existence (Terry, 1993). For Bill George (2003), the former CEO of Medtronic, the five characteristics of an authentic leader included understanding their purpose, having strong values, trusting relationships, having self-discipline, and acting from the heart (mission). A more popular definition of authentic leadership was formulated by Walumbwa, Avolio, Gardner, Wernsing, \& Peterson (2008), who suggested a framework consisting of four elements:

1. self-awareness consisting of reflecting on one's core values, identity, emotions, and motives and being aware of and trusting your own feelings;

2. an internalized moral perspective that includes a self-regulatory process using internal moral standards to guide behavior;

3. balanced processing or the ability to analyze information objectively and explore other people's opinions before making a decision; and

4. relational transparency, such as being open and honest in presenting one's true self to others.

In a 2015 Harvard Business Review article, Herminia Ibarra identified why leadership authenticity was so difficult. The central issues included being true to oneself, maintaining coherence between what is felt and the resulting actions, and making values-based choices. For women, authentic leadership is more challenging because many of the attributes of authenticity also carry the stigma of being female attributes and are thus not valued as much in a business environment. The concept of personal reflection and any reference to feelings, motives, moral perspective, 
and transparency are not seen as contributing to business results. This, therefore, may be a hint as to why women leaders may be more likely to be the subject of being scapegoated.

\section{THE STUDY}

The purpose of this qualitative descriptive study was to explore how women in senior positions of leadership in Arizona describe authenticity or authentic leadership when recovering from being the recipient of scapegoating behavior. Using purposeful selection, 15 women, ranging in age from their $20 \mathrm{~s}$ to $70 \mathrm{~s}$ with five to 40 years of experience in leadership agreed to participate. The leadership positions held by the participants included higher education, religious organizations, hospitality, and media. Eighteen interview questions guided the process lasting 30 to 90 minutes. The participants were asked to define authenticity, provide an example of it, and describe how it felt when they were authentic. All were asked to provide an example of when their authenticity was challenged. Each participant was then asked if they were familiar with the concept of scapegoating or being thrown under the bus and to provide an example of when they were scapegoated. In-depth questions were asked around this experience. Once described, the participants were asked how the scapegoating experience affected their authenticity and what lessons they learned from the experience.

\section{SCAPEGOATING EXPERIENCES}

Being the victim of scapegoating generally resulted in feelings of helplessness, disillusionment, loss of confidence, fear, physical distress, shame, and anger. Feelings of abandonment also arose. For example, Charlotte's supervisor provided all the information for a financial wire, asking Charlotte to just finish the wire transfer. The information provided was incorrect and resulted in the wrong account receiving $\$ 500,000$. Charlotte was blamed by senior management for the mistake, and her supervisor failed to step forward to accept responsibility.

Karen was directed by her boss to split two departments with conflicting personalities. When senior management questioned the decision, Karen's boss did not take ownership for the directive. Not only did Karen describe the experience as one where her integrity was attacked but she felt "betrayed and devastated. I'm not a crier, but I was pretty close in that meeting to start crying."

Emmalyn provided an example of several teams blaming each other for not following processes or using good communication. As the project began to falter, she did what she felt was right for the project, and the result was a vicious process of cross-team blaming and fear of losing her job. Emmalyn reflected that she wished she had spoken up more instead of taking a more passive stance.

When asked about the experience of scapegoating, vivid metaphors were expressed, such as "the energy gets really crackly," "sandpaper on my skin," and "It was a process. And it was psychologically torturous until I decided what I needed to do." The participants shared difficult decisions that they needed to face as they were being scapegoated. Adrienne discussed that her internal struggle was the concern for the future of her career. She explained, "I made my own decision and recognized what was more important at the time, which was I believed I needed the money. I kept my job even though my feelings were different."

The scapegoating process was described by one participant as her "nice girl mask" grew thicker to survive in the environment. Others expressed feelings of frustration, hurt, anger, fear, abandonment, depression, helplessness, or sadness for being betrayed. Others felt "set up," "taken advantage of," or knowing "who my real friends were." Some felt they had to be particularly watchful and aware in their environment to "protect themselves," while others questioned if they would have the courage to speak up about an issue in the future. Essentially, "a wall went up, I retreated behind it and hoped I would not be subjected to more."

\section{THE JOURNEY TO THE AUTHENTIC SELF}

Using the four characteristics of authentic leadership (Walumbwa et al., 2008), self-awareness was the first to be encountered during the scapegoating process. This characteristic includes reflecting on core values, identity, emotions, and motives while being aware of and trusting your own feelings, which was initially difficult for the participants. The feeling of being captured within the context of trauma made pausing for reflection difficult. One participant stated that she would be challenged in the future to get "beyond 
reacting to being blamed to trying to understand." Becoming aware of and trusting their own feelings, the participants expressed feelings of fear and concern during the scapegoating experience. Paulette described the experience as being "... . straddled over a barbed wire fence." Many of the participants felt scapegoating stripped away their self-assurance, pride, and confidence. Yet, the struggle to rediscover the authentic self provided a measure of self-assurance. Carolynn remarked that "painful experiences make you realize who you are and what you stand for." The participants in this study indicated that there were issues that challenged their beliefs of who they thought they were, their identity as a female, and their belief in their organizational leadership capabilities.

The complexities between individual and group dynamics are heighted during the scapegoating process. For example, Relational Regulation Theory (Lakey \& Orehek, 2011) explains the need for social support as a buffer to stress while Social Identity Theory (Tajfel \& Turner, 1979) espouses that individuals will seek ways to ensure they remain within the in-group rather than risk being in the outgroup. At the same time, the desire for the group's shared meaning and efforts to reduce tension and increase coherence creates further conflict between individuals (Eoyang \& Holladay, 2013). For the person being scapegoated, there is incongruence as their self-image is now in juxtaposition with withdrawn social supports, feigned genuineness, lack of acceptance, or being treated with negative regard, all of which are opposite of Carl Rogers (1959) dimensions of self-actualization. In other words, the scapegoating experience challenges all sense of reality for the recipient.

Understanding strong emotional reactions while being scapegoated was the first hurdle. Seven of the 15 women interviewed expressed anger, and all but two described their experience of being on the receiving end of blame. All participants agreed that it was difficult to maintain authenticity when being blamed, and many expressed that they did not handle the situation well. They expressed sincere confusion with the situational dynamics and wondered how to react, who would be safe to act as a sounding board, or who to trust. One participant expressed a feeling of being "disrespected, marginalized, disempowered, and entrapped." Others felt "not respected or valued" or being trapped in a passive-aggressive relationship. All felt challenged. "I felt angry," "my ethics challenged," "my integrity was questioned," "who I am as a leader was questioned." Some identified concern over professional repercussions of whether to stay or leave the organization. All participants identified an initial reaction of something being wrong either with understanding the situation or the group behavior, or they wondered if there was something wrong with them personally.

It took time for each participant to articulate the dynamics framed by the second characteristic of authentic leadership (Walumbwa et al., 2008). Defined as the internalized moral perspective or self-regulatory process using internal moral standards to guide behavior, the participants were able to describe their strong moral perspective as being one that helped them through the process and maintain their authenticity. Often this was through sheer determination. Arlene stated that she felt she needed to "keep talking until somebody hears what it is that I have to say and acknowledges it. They don't have to agree with me, but they have to acknowledge what I'm saying is true or valid or whatever word you want to say." For some participants, there was a clear difference in moral high ground. For Cassady, who felt she did not lose her authenticity in the process because "when my true core belief is being pushed, it is one of those areas where it is never grey." If her CEO sided with the CFO and had asked her to do something "that I was not comfortable with, I would have left the organization. I knew I had to just be a little more vocal and aggressive about my position, if that makes sense."

Some of the women noted that they were unable to retain their authenticity during the process, but the experience shaped who they became after the experience. Emmalyn explained, "I have to be able to look in the mirror and be okay with what I see." Many of the participants felt scapegoating stripped away their self-assurance, pride, and confidences. Yet, the struggle to rediscover the authentic self resulted in self-assurance. Carolynn remarked that "painful experiences make you realize who you are, what you stand for." Charlotte explained "You don't change based on the environment. No matter the circumstances you stick to who you are." Paulette 
stated that she "had to choose where I truly felt the most authentically me, and it was a process. And it was psychologically torturous until I decided."

The third characteristic of authentic leadership (Walumbwa et al., 2008) is the ability to analyze information objectively and explore other people's opinions before making a decision. For the participants, this became the most difficult to embrace. One participant stated that she learned she needed to be open to others' views because with a different perspective or lens, "I cannot understand what is really going on in their head, what they are really thinking and that takes patience." For another participant it was important to learn to not personalize that attack or to start attacking the other person and to get to the root of the issue "because you may not have all the facts and what's going on in their environment may be very different and may have an impact on what's going on in your understanding of the issue."

When seeking to understand a different perspective, trust becomes important. According to Zevallos \& Washburn (2014), trust is a critical component and building trust can take time. Trust is often linked to openness, mutual respect, and the willingness to seek help. For some, there was an awareness of being blamed for something they did not do. For some, an incorrectly designed work process resulted in blame for the person having to carry out the policy. For others, it was a lie that was told by another person to avoid consequences. It was this feeling of isolation that prevented most from either trusting their own instincts or reaching out to others for help and advice.

For many of the participants it was the fourth characteristic of theauthenticleadership(Walumbwa et al., 2008) that provided the greatest personal learning. Defined as relational transparency or being open and honest in presenting one's true self to others, many participants expressed that being able to admit mistakes, demonstrate vulnerability, and maintain a high standard of integrity were challenges as well as sources of personal learning for the mentors. As Grace phrased it, "the way you display integrity, even if not pretty" was the opportunity to fully live in authenticity. Arlene described that it was difficult to move beyond judgement when describing the situation to a more accepting stance:
It was like a little "ding" went off in my head. I had an epiphany. As a female, when I would get angry, I would internalize it. I would not yell at people, get mad, or throw things. I had learned to just internalized it. When I was being scapegoated, I felt like I was boiling all the time.

It took encountering the different motives, goals, or objectives of others, to enable the participants to understand some of their own personal motives. Each came to understand that authenticity is only the door to aliveness and a choice between masks on for personal safety or off for self-congruence (Quade and Brown 2002). Arlene describes this process saying:

once you begin to get who you are and what your value is - it takes courage to act. But you begin to see that not taking something head-on costs so much more than whatever you do. You begin to see how devastating that is to you as a person. And how much it steals from the people around you.

Leah identified her key learning as not being afraid or ashamed to let people know that mistakes were made and learning occurred. "You also have to be smart enough to learn from other people's mistakes. Being authentic also means letting people know you are not looking at perfection. My life is not perfection, I made mistakes." Being willing to reveal failures and embarrassing situations is the culmination of boldly owning one's true, authentic self and accepting past experiences as pivotal moments in one's development. Jennifer used her experiences to shape the advice she would give to others, which would be "to be true to yourself and that you would be more disappointed in the future if would change or conform out of fear or out of pressure from the environment."

Becoming authentic is a continuous process in which the journey takes precedence over the destination. The experiences of scapegoating played a pivotal role in the cyclical process of developing the participants authentic self. The experiences were used as valuable, albite painful, learning experience that might be described as moving away from the need to prove oneself as compared to embracing one's true self. According to Quade \& Brown (2002), the authentic person accepts themselves, warts and all, without judgment, blame, shame, or guilt. There is only the practice of living authentically, which is starting with an open 
mind, seeking to understand, being curious about possibilities, and being able to suspend judgment to learn about personal biases, assumptions, judgements, mindsets, or blind spots. According to Mertz (2009), living authentically involves the active process of reflecting, taking actions that are aligned with personal values, cultivating selfdiscipline where values influence daily decisions, and taking responsibility for actions.

While emphasizing the role of leaders, Wheatley (2017) explains that individuals need to

persevere in the face of obstacles, setbacks, slander, and hate. They have made a choice to do the right thing, clear about their values, connected to those they lead, unwilling to succumb to fear or aggression. They are committed to staying in their work, exemplars of integrity and possibility no matter what is occurring in the external environment (p. 41).

Much of this navigation cannot be predicted and only comes during moments of challenge, stress, or conflict. Many participants expressed that the most important aspect of being authentic, especially when encountering scapegoating, blame, or judgement, was to be honest, straightforward, and clear with their thoughts. Being able to admit mistakes, demonstrate vulnerability, and maintain a high standard of integrity were challenges as well as sources of personal learning. As Grace phrased it, "the way you display integrity, even if not pretty" was the opportunity to fully live in authenticity.

\section{CONCLUSIONS}

The scapegoating experience as described by the participants was complex, highly emotional and provided tremendous learning. We found from our interviews that the participants' experiences were only the tip of what can be learned about the dynamics of scapegoating at both the group and individual level. Many theories could be considered to explain the dynamics of scapegoating, and yet there is little research on what can be done to stop or redirect the process once it is in motion. One thing is certain, for the individual on the receiving end, the results are life changing. We encourage further research to understand the role of active change, the distinctions of definition for authenticity as perceived by men and women, and the role of authentic leadership by women in positions of power and authority. 


\section{REFERENCES}

Allport, G. W., \& Postman, L. J. (1948). The psychology of rumor. New York, NY: Henry Holt and Company.

Argyris, C. (1962). Interpersonal competence and organizational effectiveness. Homewood, IL: Dorsey Press.

Bonazzi, G. (1983). Scapegoating in complex organizations: The results of a comparative study of symbolic blame-giving in Italian and French public administration. Organization Studies, 4(1), 1-18. doi:10.1177/017084068300400101

Eoyang, G. H., \& Holladay, R. J. (2013). Adaptive action: Leveraging uncertainty in your organization. Stanford, CA: Stanford University Press.

George, B. (2003). Authentic leadership: Rediscovering the secrets to creating lasting value. San Francisco, CA: John Wiley \& Sons.

Girard, R. (1986). The Scapegoat. Baltimore, MD: Johns Hopkins University Press.

Ibarra, H. (2015). The authenticity paradox. Harvard Business Review, 93(1/2), 53-59.

Lakey, B., \& Orehek, E. (2011). Relational regulation theory: A new approach to explain the link between perceived social support and mental health. Psychological Review, 118(3), 482-495. doi:10.1037/a0023477

Mertz, M. M. (2009) Becoming Athena: Eight Principles of Enlightened Leadership. Sedona, AZ: MMM Publications.

Quade, K., \& Brown, R. M. (2002). The conscious consultant: Mastering change from the inside out. San Francisco, CA: Jossey-Bass/Pfeiffer.

Rogers, C. R. (1959). A theory of therapy, personality, and interpersonal relationships: As developed in the clientcentered framework. In S. Koch (Ed.), Psychology: A study of a science (Vol. 3, pp. 184-256). New York, NY: McGraw Hill.

Ruch, G., Lees, A., \& Prichard, J. (2014). Getting beneath the surface: Scapegoating and the systems approach in a post-Munro world. Journal of Social Work Practice, 28(3), 313-327. doi:10.1080/02650533.2014.925864

Tajfel, H., \& Turner, J. C. (1979). An integrative theory of intergroup conflict. In W. G. Austin \& S. Worchel (Eds.), The social psychology of intergroup relations (pp. 33-47). Monterey, CA: Brooks/Cole.

Terry, R. W. (1993). Authentic leadership: Courage in action. San Francisco, CA: Jossey-Bass.
Walumbwa, F. O., Avolio, B. J., Gardner, W. L., Wernsing, T. S., \& Peterson, S. J. (2008). Authentic leadership: Development and validation of a theory-based measure†. Journal of Management, 34(1), 89-126.

Weir, J. (1975). The personal growth laboratory. In K. D. Benne, L. P. Bradford, J. R. Gibb, \& R. O. Lippitt (Eds.), The laboratory method of changing and learning (pp. 293-325). Palo Alto, $\mathrm{CA}$ : Science and Behavior Books.

Wheatley, M. J. (2017). Who do we choose to be?: Facing reality, claiming leadership, restoring sanity. Oakland, CA: BerrettKoehler Publishers.

Zevallos, A. L., \& Washburn, M. (2014). Creating a culture of student success: The SEEK scholars peer mentoring program. About Campus, 18(6), 25-29. doi:10.1002/ abc. 21141 